DOI 10.37882/2223-2974.2020.12.19

\title{
КВАЛИФИКАЦИЯ ДЕЯНИЙ ПРИ ПРИЧИНЕНИИ СМЕРТИ ПО НЕОСТОРОЖНОСТИ МЕДИЦИНСКИМИ РАБОТНИКАМИ
}

\section{QUALIFICATION OF ACTS IN THE EVENT OF DEATH BY NEGLIGENCE BY MEDICAL WORKERS}

V. Kim

M. Yunusov

Summary: Criminal qualification for causing death by negligence by medical personnel. Introduction: the question of the criminal-legal qualification of the actions of medical workers when they cause death by negligence to patients is considered. The specifics of medical responsibility as legal responsibility are determined, and attention is also paid to the circumstances to be established by law enforcement officers in each specific case when resolving a dispute about the presence of signs of criminal behavior in the actions of a medical worker. The positions of Russian law enforcement officers regarding the qualification of the actions of medical workers as a crime under Part 2 of Art. 109 UK RF (causing death by negligence by officials - medical workers). Purpose: to substantiate the relevance of the chosen topic; to analyze the positions of the courts regarding the establishment of certain circumstances for each dispute, indicating the presence of signs of criminal encroachment in the actions of medical workers. Methods: the dialectical method as a general, universal method of study, general scientific (analysis, synthesis), private scientific (formal-logical, formal-legal) methods of scientific knowledge. Results: the circumstances were determined to be established by the court when bringing medical workers to criminal liability for committing a crime under Part 2 of Art. 109 of the Criminal Code of the Russian Federation. Conclusions: to qualify the actions of a medical worker as a criminal act, provided for in Part 2 of Art. 109 of the Criminal Code of the Russian Federation, it is necessary to establish the following circumstances: whether a medical worker has the authority to carry out medical activities in the relevant profile, medical activities in the relevant profile, the presence of a real possibility of a medical worker performing specific actions in accordance with the developed recommendations in this area; non-compliance with such recommendations, standards; the onset of consequences in the form of the death of the patient, the presence of a cause-and-effect relationship between the acts and the resulting consequences.

Keywords: medical activity, legal liability, medical error, accident, punishable omissions.

\author{
Ким Валерий Вениаминович \\ Дальневосточный федеральный университет \\ valera.kim.2799@mail.ru \\ Юнусов Микаил Фузули Оглы \\ Дальневосточный федеральный университет \\ mikail.yunusov.1999@mail.ru
}

Аннотация: Рассматривается вопрос об уголовно-правовой квалификации действий медицинских работников при причинении ими смерти по неосторожности пациентам. Определена специфика медицинской ответственности как юридической ответственности, а также уделено внимание обстоятельствам, подлежащим установлению правоприменителями в каждом конкретном случае при разрешении спора о наличии в действиях медицинского работника признаков преступного поведения. Изучены позиции российских правоприменителей по поводу квалификации действий медицинских работников как преступления, предусмотренного ч. 2 ст. 109 УКРФ (причинение смерти по неосторожности должностными лицами - медицинскими работниками). Цель: обосновать актуальность избранной темы; проанализировать позиции судов относительно установления по каждому спору тех или иных обстоятельств, свидетельствующих о наличии в действиях медицинских работников признаков преступного посягательства. Методы: диалектический метод как общий, универсальный метод изучения, общенаучные (анализ, синтез), частно-научные (формально-логический, формально-юридический) методы научного познания. Результаты: определены обстоятельства, подлежащие установлению судом при привлечении медицинских работников к уголовной ответственности за совершение преступления, предусмотренного ч. 2 ст. 109 УК РФ. Выводы: для квалификации действий медицинского работника как преступного деяния, предусмотренного ч. 2 ст. 109 УК РФ необходимо установить следующие обстоятельства: наличие у медицинского работника полномочий на осуществление медицинской деятельности по соответствующему профилю, медицинской деятельности по соответствующему профилю, наличие реальной возможности исполнения медицинским работником конкретных действий в соответствии с разработанными рекомендациями в этой сфере; несоблюдение таких рекомендаций, стандартов; наступление последствий в виде смерти пациента, наличие причинно-следственной связи между деяниями и наступившими последствиями.

Ключевые слова: медицинская деятельность, юридическая ответственность, врачебная ошибка, несчастный случай, наказуемые упущения.

и безопасных медицинских услуг «переросла» в глобальную проблему современного человечества.

В действующем Уголовном кодексе РФ предусмотрено несколько составов преступлений, субъектами которых могут выступать лица, имеющие специальное меди- 
цинское образование. Однако указание на специального субъекта в данных составах преступлений не всегда на практике приводит к правильной квалификации действий конкретного лица - медицинского работника.

Затрудняет процесс осуществления названной деятельности и то обстоятельство, что содеянное требуют за собой установления специфических признаков объективной стороны преступного деяния. В этом случае выяснение сугубо медицинских аспектов конкретных действий возлагается на специалистов-медиков. Соответственно, в таких условиях перед следователем, дознавателем стоит серьезная задача по оценке правильности представленного специалистом заключения, установлению причинно-следственной связи между совершенным деянием и наступившими последствиями.

\section{1. Понятие уголовной ответственности меАишинских работников}

Уголовная ответственность медицинских работников представляет собой особую разновидность юридической ответственности, которая возникает в связи с осуществлением лицом медицинской деятельности на профессиональной основе.

Преступления, совершаемые медицинскими работниками, содержатся главным образом в Главе 16 Уголовного кодекса РФ, а потому непосредственным объектом посягательств рассматриваемых преступлений, выступают жизнь и здоровье лица (пациента). Кроме того, в качестве объекта преступных посягательств можно также определить право гражданина на получение качественной медицинской помощи, право на получение безопасных медицинских услуг [Нестерович, $2017,136]$.

Специфика указанной разновидности преступлений сводится к тому, что осуществляемые неправомерные действия непосредственно связаны со сферой оказания лицом медицинских услуг. Соответственно, для признания такого лица субъектом преступления необходимо, чтобы лицо имело специальный документ, удостоверяющий право на оказание медицинских услуг и подтверждающий его квалификацию или специализацию.

Вместе с тем отдельные виды деяний могут быть совершены лицами, не имеющими на то специального медицинского образования (например, халатность, прерывание беременности и т.п.).

В нашем исследовании анализу подвергаются преступления, совершаемые именно медицинскими работниками при осуществлении ими своих профессиональных обязанностей и полномочий, в результате которых была причинена смерть (ч. 2 ст. 109 УК РФ).
Субъектом данного преступления могут выступать медицинские работники независимо от их статуса, направления деятельности, объема предоставленных полномочий. К числу таких лиц могут быть отнесены: врачи, фельдшеры, медицинские сестры, санитарки и т.п. [Нестерович, 2017, 138]

\section{2. Уголовная ответственность меАишинских работников по ч. 2 ст. 109 УК РФ}

Ранее действовавшее законодательство приравнивало причинение смерти по неосторожности к убийству (ст.106 УК РСФСР).

Состав преступления, предусмотренный ч. 2 ст. 109 УК РФ в качестве потерпевшего рассматривает исключительно пациента, то есть лицо, проходившее соответствующее лечение под присмотром виновного в совершении преступления. Объектом выступает жизнь человека.

Объективная сторона рассматриваемого преступления представлена как действиями, так и бездействиями, в результате которых пациенту был причинен вред, не совместимый с жизнью. При этом следует учитывать, что такие действия явились «предпосылкой» для действительного наступления столь тяжких последствий.

В судебно-медицинской литературе неправомерные действия медицинских работников, совершаемые в процессе осуществления профессиональной деятельности, именуются как «неблагоприятные исходы лечения». К числу таких деяний относятся:

- врачебные ошибки - добросовестное заблуждение медицинского работника в диагнозе, способах и методах лечения и т.п. Указанные «несовершенства» обусловлены наличием на то объективных и субъективных причин, например, в связи с низким уровнем профессионализма медицинского работника, отсутствием у него необходимых теоретических знаний, знаний об использовании того или иного медицинского прибора, аппарата. Следовательно, указанные последствия являются «пороками» компетенции, профессионализма медицинского работника, а потому такое лицо не подлежит привлечению к уголовной ответственности [Давыдов, 2011, 45]. В этом случае отказ законодателя от привлечения медицинского работника вполне оправдан, поскольку в действиях лица отсутствует какой-либо умысел, а совершаемые им действия расцениваются последним в качестве верных, целесообразных в соответствующих условиях.

Так, у И. в качестве симптомов наблюдались высокая температура, головная боль, рвота, на основании чего было указано на наличие инфекции. 
Вместе с тем, указанные признаки могут свидетельствовать и об ином диагнозе. По результатам рассмотрения уголовного дела было установлено, что у И. развился отек головного мозга, что и явилось непосредственной причиной смерти. В этой связи в действиях 3. судом было установлено, что имелась врачебная ошибка в установлении диагноза больному И. [Апелляционное постановление Брянского областного суда]. В этом случае лицо не могло быть привлечено к уголовной ответственности, поскольку 3. были предприняты все необходимые действия 3. в рамках установленного диагноза, а выявить отек мозга по имеющимся симптомам не представлялось возможным.

- несчастные случаи - это неблагоприятные последствия медицинского вмешательства, которые невозможно было предвидеть при оказании медицинской помощи лицу. В этом случае медицинским работником могут быть предприняты все необходимые действия, направленные на предотвращение соответствующих негативных последствий, в силу наличия на то каких-либо объективных причин и обстоятельств. Следовательно, в этом случае медицинским работником предпринимаются все необходимые действия, направленные на поддержание жизнеспособности лица, однако в силу определенных объективных причин, неблагоприятные последствия все же возникают. Поскольку действия медицинского работника в таких условиях являются правильными и целесообразными, то такое лицо не подлежит привлечению к уголовной ответственности [Воропаев, 2007, 115]. Так, при лечении К. осознанно не сообщила о наличии у нее аллергии на пенициллин. При назначенной дозировке указанного препарата в процессе лечения у К. развился аллергический шок, и как следствие привел к летальному исходу. Вместе с тем, суд пришел к выводу о том, что в действиях медицинского работника отсутствуют признаки преступления, предусмотренные ч. 2 ст. 109 УК РФ, поскольку М. были предприняты все необходимые для лечения К. действия, однако в силу обстоятельств, не известных М. наступили такие тяжки последствия [Решение Стародубского районного суда Брянской области].

- наказуемые упущения. В отличие от вышеназванных действий указанная модель поведения характеризуется особой общественной опасностью, что связывается с недобросовестным оказанием лицом медицинских услуг на профессиональной основе.

Действия при врачебной ошибке и несчастном случае не являются неверными, нецелесообразными, а потому уполномоченное лицо в этом случае освобождается от уголовной ответственности. Напротив, наказуемые упущения имеют место в случаях совершения медицинским работником действий, имеющих за собой объективные причины недостатков, упущений в диагностике и лечении.

Как же отличить врачебную ошибку от наказуемых упущений? Представляется, что в этом случае правоприменителем должны быть приняты меры, необходимые для установления модели поведения медицинского работника в сложившейся ситуации. Здесь должно быть установлено, предпринимались ли таким лицом действия, направленные на оказание пациенту медицинских услуг в соответствии с поставленным диагнозом. Соответственно, если такое лицо предприняло и совершило все зависящие от него действия, направленные на лечение лица в рамках поставленного диагноза, то в его действиях отсутствует состав уголовного преступления. При этом не имеет значения правильно либо неправильно был установлен диагноз по имеющимся симптомам протекания болезни. В ином же случае следует говорить о фактическом бездействии лица, неисполнении им своих профессиональных обязанностей в соответствии с его квалификацией, специализацией.

Установление в действиях медицинского работника наказуемых упущений возложено на врачей-специалистов в соответствующей области либо судебно-медицинских экспертов. Так, при расследовании уголовного дела по обвинению К. в совершении преступления, предусмотренного ч. 2 ст. 109 УК РФ, была назначена экспертиза, в ходе которой было установлено следующее. К. как врач-педиатр не провела полный осмотр В., недооценила тяжесть клинических проявлений заболевания, эпидемиологическую обстановку и поставила неправильный диагноз, в результате чего у последней появились осложнения основного заболевания. В этом случае К. должна была, по мнению экспертов, госпитализировать В. Однако указанные действия не были предприняты, в результате чего В. Скончалась [Приговор Благодарненского районного суда].

При этом разрешение вопроса о привлечения медицинских работников в уголовной ответственности по ч. 2 ст. 109 УК РФ вопроса требует за собой учета следующих обстоятельств:

1. Ограниченность познаний медицинских работников в соответствующих областях знаний, препятствующих назначению необходимого лечения, проведения диагностики, профилактики развития опасных для жизни и здоровья последствий, осложнений у пациентов.

2. Отсутствие необходимого оборудования, аппаратуры, их несовершенство в пределах отдельного медицинского учреждения, что не позволяет правильно диагностировать заболевание.

3. Специфичность протекания заболевания, ред- 
кость и злокачественность заболевания.

4. Несоответствие предоставленных медицинскому работнику прав и обязанностей фактическому объему осуществляемых полномочий.

5. Исключительность особенностей организма конкретного пациента, специфики влияния на его организм отдельных лекарственных препаратов.

6. «Усугубление ситуации» самим пациентом, его родственниками и близкими лицами (например, невыполнение рекомендаций лечащего врача, позднее обращение за медицинской помощью и т.п.).

7. Особенности психофизиологического состояния медицинского работника (утомляемость, наличие заболевания и т.п.) [Воропаев, 2007, 117].

Названые обстоятельства могут явиться следствием наступления такого неблагоприятного последствия, как смерть. В свою очередь, если такое последствие возникло в связи с неоказанием пациенту необходимой медицинской помощи, ее неправильном предоставлении, то такие действия (бездействия) медицинского работника приобретают признаки уголовно наказуемого деяния (преступления).

Признаки преступления, предусмотренного ч. 2 ст. 109 УК РФ, были установлены и в деянии Ч. - врача-педиатра. Указанным лицом также не был проведен полный осмотр пациента, не были назначены необходимые анализы, что привело к постановке неправильного диагноза. В свою очередь, отсутствие должного лечения Л. привело к существенному ухудшению здоровья последнего, смерти [Постановление Калужского районного суда].

При этом необходимо учитывать, что лечение того или иного заболевания может строиться на основе одного из двух (или нескольких) вариантов лечения. Право выбора в этом случае принадлежит медицинскому работнику на основе и в соответствии с конкретной обстановкой проведения лечения, особенностями организма пациента, а также практическим опытом, знаниями лечащего врача и т.п.

В свою очередь, ненадлежащее исполнение медицинским работником своих профессиональных обязанностей будет иметь место лишь в том случае, когда таким лицом в противоречие имеющимся исследованиям, разработкам и рекомендациям (полностью либо частично) были совершены либо не совершены необходимые действия, что повлекло за собой возникновение неблагоприятных последствий для пациента [Петрова].

Важным элементом объективной стороны преступления, предусмотренного ч. 2 ст. 109 УК РФ (причинение смерти по неосторожности медицинскими работниками) являются неблагоприятные последствия в виде смерти пациента. Здесь важным элементом состава преступления является причинно-следственная связь между преступным поведением медицинского работника и наступившими последствиями в виде смерти пациента. Так, К., врачом-хирургом, в результате проведения неполного обследования пациента не была выявлена острая хирургическая патология. В этой связи своевременная медицинская помощь В. не была оказана. В результате развития патологии В. скончался [Приговор Алексинского городского суда]. Суд установил, что между действиями Костюкова В.С., дефектами оказания им медицинской помощи ФИО1 и наступлением неблагоприятного исхода (смертью) имеется причинно-следственная связь.

Необходимо также учитывать, что медицинский работник должен иметь реальную возможность осуществления своих полномочий надлежащим образом. Иными словами, должны иметь место нормальные условия оказания медицинских услуг, соответствие профессионализма, опыта, знаний и необходимой квалификации медицинского работника, наличие технического оснащения, наличие которых позволяет выполнить необходимые действия в полном объеме и в правильной последовательности. Соответственно, в этом случае исключаются какие-либо объективные обстоятельства, которые воспрепятствовали бы нормальному осуществлению профессиональной деятельности. Так, К., имея все необходимые условия для проведения полного обследования пациента, обладая необходимыми знаниями, провел лишь внешний осмотр пациента с частичным обнажением верхней части туловища. Вместе с тем фельдшера станции скорой медицинской помощи указывали К. на возможные переломы ребер у пациента, а также подозрение на черепно-мозговую травму и необходимость, в связи с этим проведения рентгенографического исследования. Кроме того, внешний вид (кровоточащая рана, множественные кровоподтеки и ссадины) и физическое состояние (слабость, нарушенная координация, передвижение с помощью других лиц) с очевидностью требовали от дежурного врача тщательного обследования больного. Несмотря на наличие у пациента телесных повреждений, угрожавших его жизни и здоровью, К. каких-либо иных мер, кроме дачи указаний медицинской сестре по обработке раны в проекции правой надбровной дуги не предпринял. С учетом имеющихся патологий потерпевший умер [Постановление Скопинского районного суда].

При установлении субъективной стороны рассматриваемого деяния необходимо установить, владело ли лицо соответствующими знаниями, должно ли было такое лицо владеть такими знаниями. Уголовная ответственность в этом случае будет иметь место тогда, когда медицинским работником в соответствии с его компетенцией, специальным образованием осознавался факт взаимосвязи его противоречащих медицинским 
рекомендациям действий с возможным наступлением неблагоприятных последствий. Так, например, Судебная коллегия по уголовным делам Магаданского областного суда установила, что А. является сотрудником МУз «МРД», где в течение 5 лет осуществляла свои должностные обязанности в соответствии со специальностью «акушерство и гинекология». При наблюдении М., состоящей на учете по беременности, А. не были предприняты необходимые действия, совокупность которых позволила бы М. выносить и родить здорового ребенка. Судом были выявлены следующие нарушения А. в процессе осуществления своей медицинской деятельности: не были назначены необходимые анализы, не проводился осмотр пациентки, не назначила лечения с учетом имеющихся показаний [Кассационное определение Судебной коллегии по уголовным делам Магаданского областного суда]. Следовательно, в этом случае медицинский работник умышленно не совершил необходимых действий, которые требовалось бы осуществить при оказании медицинских услуг в «обычных» условиях.
Субъективная сторона рассматриваемого состава преступления характеризуется неосторожной виной в виде легкомыслия или небрежности.

\section{Зак^ючение}

Таким образом, уголовная ответственность медицинских работников за причинение смерти по неосторожности может иметь место при наличии следующих условий:

- несоблюдение медицинским работником стандартов, инструкций осуществления тех или иных действий при лечении соответствующего заболевания;

- наличие реальной возможности исполнить медицинским работником свои профессиональные обязанности надлежащим образом;

- наступление последствия в виде смерти пациента;

- наличие причинно-следственной связи между совершенными деяниями и наступившими последствиями.

\section{ЛИТЕРАТУРА}

1. Апелляционное постановление Брянского областного суда по делу № 22-354/2020 от 3 марта 2020 г. URL: https://clck.ru/RfAgK

2. Воропаев А.В. Некоторые аспекты уголовной ответственности медицинских работников за причинение смерти по неосторожности при исполнении профессиональных обязанностей // Сибирский медицинский журнал. 2007. № 3. С. 115-117.

3. Давыдов Р.А. Причинение смерти по неосторожности. Врачебная ошибка. Понятия, сравнение, анализ // Молодой ученый. 2011. № 6 (29). С. $45-48$.

4. Кассационное определение Судебной коллегии по уголовным делам Магаданского областного суда по делу от 28 aпреля 2010 r. URL: http://oblsud.mag. sudrf.ru/modules.php?id=546\&name=docum_sud.

5. Нестерович И.Ю. Уголовная ответственность медицинских работников как вид юридической ответственности // Молодой ученый. 2017. С. 136-139.

6. Петрова Т.Н. Ошибки квалификации профессиональных преступлений медицинских работников. URL: https://e.ugpr.ru/542444.

7. Постановление Калужского районного суда по делу № 1-592/2019 от 20 ноября 2019 г. URL: https://clck.ru/Rf8aj.

8. Постановление Скопинского районного суда Рязанской области по делу № 1-129/2018 от 12 ноября 2018 г. URL: https://clck.ru/Rf9dd.

9. Приговор Алексинского городского суда Тульской области по делу 1-1/2019 от 15 января 2019 г. URL: https://clck.ru/Rf8kT.

10. Приговор Благодарненского районного суда Ставропольского края по делу № 1-15/11 от 22 февраля 2011 г. URL: http://www.gcourts.ru/case/6415657.

11. Решение Стародубского районного суда Брянской области по делу № 2-654/2013 от 21 ноября 2013 г. URL: https://sudact.ru/regular/doc/7bAVEoJsaV. 